Journal of Universal Language 7

March 2006, 1-28

\title{
Reported Speech: Towards a Definition as a Communicative and Linguistic Universal
}

\author{
Annamaria Cacchione
}

La Sapienza University of Rome

\begin{abstract}
Reported speech is a structure that has quite always been investigated from a formal point of view, as the syntactical means by which we can construct the oratio, choosing between embedding or un-embedding sentences, respectively within oratio obliqua or oratio recta. The purpose of this essay is arguing that reported speech corresponds to a universal communicative function, the reporting function, which can realize and show itself as a multiplicity of forms, grouped around few main types, among which one in particular-direct speech-can be considered its formal universal side. So we will first define the traditional syntactical account of RS; next, we will turn to a wider perspective, in which functions are prior then forms. The functional and pragmatic account of RS will be considered the proper theoretical framework in order to identify the universal features of reporting. Finally, we will present the results of some sperimental researches about the acquisition of RS both in L1 and L2. The results will allow us to confirm the main hypotheses: the universality of RS as a basic communicative function, and the universality of (at last) one formal fulfillment of it, the direct speech, related to its prototypical
\end{abstract}


2 Reported Speech: Towards a Definition as a Communicative and

narrative function.

Keywords: reported speech, narrative, rhetoric, direct and indirect speech, theory of mind, L1 and L2 acquisition

\section{What is Reported Speech}

\subsection{The Traditional Definition of Reported Speech}

Treating reported speech (henceforth RS) as a universal element of language could be considered a little bit strange, since we (at last those who belong to the occidental culture area) use to think to it as a syntactical structure. RS is in fact the hyperonymous term that gathers the main grammatical ways in which a discourse, made in a certain time by a certain person, can be reported by a different (or even the same) person in a different time.

Traditionally, these main ways correspond to direct and indirect speech (henceforth DS and IS) - often indicated also by the Latin terms oratio recta and obliqua; sometimes, other two forms, the so called free ones, can be added, so there can be a main form of direct speech and its corresponding free one (free direct speech) and a main indirect speech with its corresponding free one (free indirect speech). ${ }^{1}$

Supposing the original speech is the first reported below, the following four sentences exemplify the four types of RS:

(1) Original speech: "What on earth shall I do now?"

(2) Direct speech: Mary said: "What on earth shall I do now?"

\footnotetext{
${ }^{1}$ In spite of many attempts to demonstrate the non literary nature of the free forms, it seems quite clear that they actually are literary, since they can be found very rarely in ordinary spoken conversation, and always making some kind of forcing.
} 
(3) Indirect speech: Mary wondered what she should do.

(4) Free direct speech: An so, in the dark, Mary wondered if there was still a chance for her. What on earth shall I do now?

(5) Free indirect speech: She was deep in thought. What on earth should she do now?

This account is based on the following assumption: there is a person, that, in certain time, utters some words, makes a discourse; some time after, another person (or even the same person) re-tells those words, reporting it and making so a reported speech. If he/she reports it choosing to be totally faithful to the first discourse, he/she will chose the direct form, otherwise, there will be the indirect form to be chosen.

Strictly linked with this theory, there are two main problems: DS is the faithful and true speech, since it corresponds to the original one, of which it is a kind of "sound photography"; indirect speech is a derived speech, a speech of second level, since it comes from a series of transformation operations, and, so, is implicitly unfaithful.

Researches in the last few decades have righted this view-based on a traditional syntactical account that presupposes an original utterance and a set of decontextualized operations which transform direct into indirect speech (Baynham 1996) - arguing that it is actually caused by a misunderstanding about the real status of RS. But the assumption illustrated before-and, in particular, what is called the verbatim assumption (Clark \& Gerrig 1990) about direct speech-still remains strong, especially in didactical application, as we all know (learning a L1 and/or a L2) if we just try to remember all the boring exercises the teacher told us to make in order to transform the direct into the indirect speech, taking care, besides, in using and changing tenses in the embedded sentences, and in so 
4 Reported Speech: Towards a Definition as a Communicative and

doing reinforcing the awareness that it was just a syntactical and formal matter.

\subsection{New Studies and Investigations}

As it has been said before, researchers made clear the notion of RS, removing the truth and faith assumption, with all the implications such as the derived nature of indirect speech etc. Essentially, the problem has been moved from a mere syntactical perspective to another, more complex one, in which the pragmatic component has the priority. According to the main results of these investigations, direct and indirect speech are just the more common forms through which one can report speeches, but they both are on the same level of faithfulness - or un-faithfulness - and on the same level even with many other forms, such as, first of all, reported discourse without any introducing element (6), that are, as it will be shown in details forward, basic emergencies of reported speech, both in L1 and L2 acquisition, corresponding to what Calaresu (2000, 2004) calls textual islands.

(6) And then while we were going into the underground "the ticket, the ticket!"

Through the contributions of many researchers, especially in France, United Kingdom and America, it has been designed a new kind of approach, basically functional, since it has been clear that the prior thing is not this or that syntactical form, but the reporting function-i.e., the possibility, that language provides to speakers, of re-telling a past speech, or imagine a future or hypotetic speech. So, in this way, it becomes more and more evident why it is possible to analyse RS as a universal structure. First of all, it corresponds to a function, that is to report, re-word, re-tell other people's words, or to imagine, to build up a future or eventual discourse, or even to 
present a speech as a RS, i.e., just uttered in a certain time and place by someone while it has actually never been said - all possibilities, especially the last ones, that were totally darkened by the traditional syntactical account.

So now, in order to highlight the universal features of RS, we can re-shape the whole question as follows.

Picture 1. Functions and Forms of RS

\begin{tabular}{|c|c|c|c|}
\hline \multicolumn{4}{|c|}{ REPORTED SPEECH } \\
\hline \multicolumn{4}{|c|}{ MAIN FUNCTION } \\
\hline \multicolumn{4}{|l|}{ Reporting } \\
\hline \multicolumn{4}{|l|}{ SUB-FUNCTIONS } \\
\hline \multirow[t]{2}{*}{ narrative } & \multicolumn{3}{|l|}{ non-narrative } \\
\hline & \multicolumn{3}{|c|}{$\begin{array}{l}\text { rhetoric, argumentative, exemplificative.... } \\
\text { appreciative, supporting, of authority... } \\
\text { dramatizing, social distancing, } \\
\text { of involvement... }\end{array}$} \\
\hline \multicolumn{4}{|c|}{ Лु } \\
\hline \multicolumn{4}{|c|}{ FORMS } \\
\hline \multicolumn{2}{|c|}{$\begin{array}{c}\text { direct } \\
\text { speech }\end{array}$} & \multirow[t]{2}{*}{$\begin{array}{l}\text { indirect } \\
\text { speech }\end{array}$} & \multirow{2}{*}{$\begin{array}{c}\quad \ldots \\
\text { other forms }\end{array}$} \\
\hline $\begin{array}{l}\text { DS without } \\
\text { introduction }\end{array}$ & $\begin{array}{l}\text { DS with } \\
\text { introduction }\end{array}$ & & \\
\hline
\end{tabular}

\section{A Pragmatic and Functional Framework}

RS is a term that corresponds to a particular linguistic function: the possibility of creating a multi-level discourse, embedding (not only from a syntactical point of view, but, most of all, from a textual, discursive and pragmatic one) different parts of discourse coming from different sources.

Basically, this function allow us to report other people's words, 
6 Reported Speech: Towards a Definition as a Communicative and

and that is the reason why it is called RS, even if, as it will be discussed below, to make a RS is not necessary to really have a real original discourse to re-tell, since it is a mechanism that make possible all the cases of inserting a speech into another one (without any theorical limit of levels but those on human memory) and, therefore, even those regarding future or hypothetical, i.e., fictitious, speeches.

The main, general function of RS - that, how it will be illustrated in details below, derives from a special semiotic property - can be articulated in several sub-functions, groupable into two main categories: narrative vs. non-narrative (sub)functions.

\subsection{The Narrative Function}

Narrative sub-function is the most studied and common one in RS. For this reason, it has been always considered the only one, and only few scholars (Vincent \& Perrin 1996, Baynham 1996) in the last years have suggested that there are other important functions.

Nevertheless, this sort of prejudice is not without reason, since the narrative function is strictly related with the semiotic roots of RS, of which is probably the prototypical function and from which all the others derive.

In fact, even if stories are not made only by dialogues, i.e., RS, voices and characters represent a huge and important part of them.

The possibility of making a speech-displacement, a sort of metadiscourse, embedding speeches into the uttered speech is in fact essential for the human expression capacity.

From a syntactical perspective, it is important to highlight that RS function is based on the stand-by property (Simone 1990). Having the possibility of stand-by means that a code can temporary interrupt itself, in order to allow the insertion of an external segment/discourse (Simone 1990: 37): 
[...] codes can be divided into two main categories: the ones allowing to generate messages that can be interrupted and the ones that do not allow it. Verbal languages belong to the first category [...] In other words, the code admits messages in which the main string 1 is interrupted in order to open a secondary string; when the second sequence ends, the first one starts again.

So it is quite clear that the stand-by property is an extraordinary resource, and it is strictly related to the structure of each text and discourse.

The stand-by possibility, helped by the elements indicating the relationships between the different parts of the message - the cohesive elements, allows the fulfilment of many different phenomena, among which there is quotation and de-quotation (Hockett 1968). ${ }^{2}$

The quotation phenomena evidently correspond to the reportive function, i.e., to RS. Besides being human-verbal-language-specific, it allows the birth of another very important property, human-verballanguage-specific too: narrative. Thus, we can say that having the stand-by mechanism and being provided with quotation possibility makes verbal languages narrative codes (Simone 1990: 81-84).

\subsubsection{RS as a Universal}

This property is shared by all verbal languages of the world, distinguishing them from other sign systems (Hockett 1966: 13).

As Haberland (1986) observes, it seems in fact quite impossible to figure out a language that cannot allow reporting in any way. Lacking that property, there would be many deep consequences, corresponding to all the sub-functions that could not be fulfilled: all the narrative related.

\footnotetext{
${ }^{2}$ De-quotation corresponds to the virtual deletion of the uttered elements.
} 
8 Reported Speech: Towards a Definition as a Communicative and

Reporting another utterance (either one's own or another person's) must come close to a universal of linguistic action. It requests quite an effort to imagine a language where it would not be possible. To begin with, we cannot exclude repetition of that other utterance [...] Of course there is still the possibility (unlike though it may be) of a culture where one simply does not report people's utterances, not even one's own. Until such a culture is discovered, we may maintain the idea that reported speech is a universal of human actions (Haberland 1986: 219, italics in original).

No stories, no novels and probably nor even books, no religion, no memories: a great part of our daily life would be totally different, and communication would be limited to very short and poor messages.

Moreover, from a cognitive point of view, we know that narrative is the main way through which we can structure our concept of reality, our identity, since the very early stage of our life (Bruner 1986).

While growing up and exploring the world around them, children re-build continuously in their mind what they have seen, herd and touched, re-telling in their inner language the story of the just past day, the party with friends, the morning at the school, the new known games, and, in doing so, retracing what happened-actions, events, words, and so on - they can understand reality, themselves and the others. So, in this sense, «storytelling is a means by which humans organize and understand the world, and feel connected to it and each other» (Tannen 1988: 92). According to Labov's model of narrative (Labov \& Waletsky 1967, Labov 1972), a story is the product of a complex process of selecting what is relevant within an event, what has a point and, so, is tellable. In this process, the storyteller has a crucial role, since he interprets the story, showing through it his subjectivity and self-identity. As Gonzàlez (2004: 18) points out: 
The print of the informant is present throughout the whole account [...] by the use of evaluative devices, whose main function is to show that the story has a point; prosody, repetition and direct quotes are the main means used by the narrator for expressive purposes [...] it is important to bear in mind that the ultimate goal of the narrator is to convince the listener, not present at the time of the event, that something important took place in the past and that the account is, therefore, worth listening to (italics in the original).

So, even our way to understand reality, in absence of the possibility of reporting, should be very different.

\subsection{The Non-narrative Functions}

In the words of Gonzàlez, quoted above, there is a clear relationship between the way narratives are built up and the use of special evaluative devices, which are used by the storyteller to organize the material and to signal which are the important things to pay attention to. The whole apparatus, besides, is seen as a means to achieve an effect in the hearer, convincing him of something or to do something, and, so, even stories actually have a very pragmatic aim, and contains, besides the narrative features, lots of argumentative and rhetoric elements - in any cases, non-narrative features.

That is the reason why, moving from the labovian framework and basing on the results of a study about spontaneous discourse, Vincent \& Perrin (1999: 293) can claim that «any utterance that does not correspond an event in a story must have a status other then narrative», and «non-narrative traits have to do either with the 
10 Reported Speech: Towards a Definition as a Communicative and

communication of emotions or with argumentation». ${ }^{3}$

Their analysis comes to the individuation of three main nonnarrative-i.e., in a labovian terms, when the aim is not to move a story along chronologically — functions of RS (ibid.):

1. an appreciative function, when RS reproduces a distinct point of view on order to highlight an event:

(7) J'étais heureuse parce-que c'était normal. J'était pas heureuse à cent our-cent parce-' J'avais des petites antennes qui me disait Hum c'est pas un choix merveilleux. Mais enfin: je me disais Je me trompe peut-être, hélas je me trompe pas. ${ }^{4}$

[I was happy because it was normal. I wasn't a hundred percent happy 'cause my sensors were telling me $H m$, it's not a great choice. But after all: I said to myself Maybe I'm wrong, but no, I wasn't wrong.]

2. a support function, when RS illustrates a metadiscoursive comment uttered by the speaker; examples, justifications or paraphrases are the most frequent forms of this function:

(8) Et puis mon mari lui: s'en mêlait pas [de l'éducation des enfants]. Fallait que les enfants le supplient Viens donc puis Viens donc puis On aimerait donc ça puis là il finissait par venir faire un tour. Mais d'ordinaire il nous empoissonnait

3 The study of Laurent and Perrin has been carried out on a corpus of 132 sociolinguistic interviews in French language, since all the informants were French speakers born and raised in Montréal (Canada). The examples quoted above are taken from their study and correspond, respectively, to the example 4 (Laurent \& Perrin 1999: 296), 6 (Laurent \& Perrin 1999: 298) and 10 (Laurent \& Perrin 1999: 301). The introductions in English are provided by the authors.

${ }^{4}$ In the examples bold is used to signal introductive elements (i.e., verbs of saying) and italics for RS. 
notre vie en éntant plein de sévérité Puis Fais pas ça puis Crie pas comme ça puis Saute pas.

[And then my husband, he: didn't get involved (in the children upbringing). The kids had to beg Please come and Please come and we'd really like you to and then he'd finally come over for a while. But most of the time he made our life miserable by being so strict with Don't do that and Don't scream like that and Stop jumping.]

3. an authority function, when the speaker uses RS in order to appeal to authority:

(9) Ah Seigneur [...] comme le médecin disait, il disait: Placez un enfant renfermé dans un appartement il dit Un enfant en bas âge, junqu'à l'âge de trois ans: quatre ans. Il va venir là il va être pareil coome un chien. Il va faire: la même réaction qu'un chien. Puis c'est réellement vrai: Seigneur. [Ah Jeez [...] like the doctor said, he said Take a kid and shut him up in an apartment he said A little kid, until he's three: four years old. He's gonna wind up he's gonna be just like a dog. He's gonna do: react just like a dog. And that's the truth: Jesus]

In a paper of just few years before, Baynham (1996) investigates the non-narrative functions of $\mathrm{RS}$ - in particular of $\mathrm{DS}$ - of mathematical adult classroom discourse, trying to understand these functions «in terms of the range of communicative resources/options available to speakers in a given discourse context» (Baynham 1996: 68), i.e., trying to understand how speakers value the several communicative means they are provided in order to fulfil certain functions, what is the place of RS among other means and how speakers manage in its use for non-narrative purposes.

Baynham's findings are quite interesting, since he can 
12 Reported Speech: Towards a Definition as a Communicative and

demonstrate that in the analyzed texts there is «an extraordinary rich texture of speech reporting and reference, which serves, in the discourse context, to dramatize in different ways the processes of mathematical reasoning as well as creating and maintaining interpersonal relations between participants» (Baynham 1996: 69).

So the non-narrative functions of RS (in the form of DS) correspond to a dramatizing function, to an involvement function and to a strategic device to manipulate social distance between participants in contexts, like classroom, where power (i.e., knowledge) is not equally distributed - a sort of social distancing function. 5

Here there is an example of Baynham's analysis: He recognizes two RS occurrences in each of the following teacher's turns (that are not adjacent in the conversation):

(10) $O k$, mathematically what Ruth and some other were doing, they - they were saying "what number will go into the top number and to the bottom" [draws a circle round the 5 in 7/5]. And you say [writing the dividing sign followed by 5 at the side of both the 7 and the 5 in 7/5] "how many fives in five". 6

(11) What Jenny said here is if you have a number after the point it is less than a whole. And here Jenny said you can change it into a fraction. (Baynham 1996: 72, bold and italics not in the original)

Going back in the videotape he can compare (10) and (11) with the following fragments:

\footnotetext{
${ }^{5}$ Involvement, as one of the main function of RS, has been focused in particular by Tannen (1989).

${ }^{6}$ See note 4.
} 
(10) a. Ruth: Five out of five is one and the two ... you just [shrugs] ... you can't do anything with it, so you just put it over five.

Diane: There's two let so you then-you use the five as the bottom number.

(11) a. Jenny: Decimals are usually where the point's in front. Teacher: $\mathrm{mm}$... mm.

Jenny: And you have numbers after it so it's not a whole number.

Sometimes decimals can be-you can make a decimal into a fraction ... you can change it.

Baynham observes that the teacher uses the resources given by different form of RS in order to reformulate what students said or did, shifting the discourse toward a more precise and scientific register. This, for example, is clear by the use of mathematically, meaning "as participants in a mathematical discourse".

Very interesting the teacher's hesitation between doing and saying (in the first line quoted):

... what Ruth and some of the others were doing, they-they were saying ....

Since it reproduces the tension between mathematical practices as activity and as meaning, and above all, because it shows clearly how speakers identify, at last in certain contexts, saying and doing, actions and words, that is the main principle of pragmatics.

The data and results from the two studies mentioned earlier have shown that there are several different non-narrative functions that RS can fulfil. Both the studies regard English or French, and make no reference about other kind of languages.

So, which are the conclusions about the universal values of these 
14 Reported Speech: Towards a Definition as a Communicative and

non-narrative functions of RS?

While there are many investigations that prove that RS is present in many languages all over the world, belonging to different language families and types, and, so, it is possible to consider RS as a linguistic universal, we lack wider studies about RS functions different from the narrative one-that we can consider as the prototypical one, and so not detachable from the reporting function.

Findings like those of Vincent and Perrin or of Baynham show us how RS can be used as a powerful communicative way to help speaker to achieve his pragmatic goals: convince the hearer about something, give force to an argument, exemplify a situation or a concept, state a particular point of view etc.

All these RS sub-functions are likely derived from the main one, that is the narrative, as overtly Baynham points out- «I will argue that direct speech in such non-narrative contexts can be seen as a feature of narrativity with multiple functions in discourse (1996: 61)»- and it could be considered as an argument supporting the hypothesis that not only the main narrative function, but even the related non-narrative sub-functions are universal. In fact, there is no reason to rule out the possibility to make examples of something important (a situation, an idea etc.) by means of RS as an universal communicative and linguistic possibility, and we can say also the same thing about the evaluation sub-function, or the involvement one (this last, in particular, seeming to be one of the most important from a communicative and affective point of view).

But we also cannot exclude the eventuality that some, or all, the non-narrative functions are cultural based, and in being so, not universal. As Li (1986) highlights, there is for example a cultural reason for the non-occurrence of certain forms of RS ( $\mathrm{Li}$ refers to IS):

In Paez culture, a person is not allowed to quote by taking the responsibility for the quote himself/herself-which is the 
implication of an indirect quote. A quote must be entirely attributable to the original speaker, in form and content - which is the strategy of a direct quote ( $\mathrm{Li} \mathrm{1986:40).}{ }^{7}$

We can imagine that mechanisms like the one illustrated by $\mathrm{Li}$ could also operate in other ways, not allowing the use of RS with one or all the mentioned functions (or even others still not investigated). Subsequently, before concluding that, as RS is universal, all its related sub-functions are universal as well, we certainly need more evidences from more language-based investigations.

\subsection{The Fulfilment of Reporting Function: Basic Forms and Other Ones}

Picture 1 in subsection 1.2 describes the pragmatic and functional model of RS, illustrating, on the upper part the functions and, in the lower, the forms that can fulfil reporting and one or more sub-functions.

On the formal and syntactical side, in its most common form (at last for occidental languages as Italian, English, French, German etc.), RS can be described by the following scheme:

$\mathrm{X}+$ speech act verb $+[$ that $] \mathrm{P}$

$\mathrm{P}$, being the quote, i.e., «a reproduction of distinct speech or thought that is reported by the reporting utterance, which, itself, is centred on a speech act verb» (Vincent \& Perrin 1999: 291). This scheme can account both for the two main forms-DS and ISdepending on whether we include or exclude subordination elements like that, that signals the embedding of the following sentence in the

\footnotetext{
${ }^{7}$ Paez is a member of the Macro-Chibchan linguistic family of South America.
} 
16 Reported Speech: Towards a Definition as a Communicative and

first one.

From a syntactical-pragmatic point of view, the same two forms can be described in terms of deictic centres organization. This approach is much more interesting than the mere syntactical one, since it can account for some differences, also of cultural type, in the use of RS among languages.

The notion of deictic centre (that other scholars call discoursive centre or origo) is defined by the coordinates of ego-hic-nunc (explicit or implicit markers of person, space and time): deictics do, in the same time, the function of structuring and "spy" of the different kind of orientation that segments of sentences assume, varying a function of RS fulfilled. ${ }^{8}$

This account is based on the clear distinction between empirical persons and discoursive roles: «the empirical persons, identifiable in their existential reality, are the characters of the speaker and of the hearer. Discoursive roles are instead the locutor and the allocutor» (Calaresu 2000: 23, 2004: 84). Once stated this distinction, it is possible to claim that, in RS in direct form, the same speaker assumes always the role of at last two locutors, while in IS there is always one only locutor, who assumes the enunciative responsibility of all the others, with the pris en charge of their utterances. ${ }^{9}$

The following examples illustrate how deictic orientation varies in the case of DS and of a IS.

\footnotetext{
8 The notion and the term origo date back to Bülher (1934).

9 The notion of pris en charge has been developed in French Linguistics, and in particular in the poliphony theory (coming from Bachtin through Ducrot et al.) to explain the different assumption of enunciative responsibility. See also Maingueneau (1998).
} 
DS [two discorsive centres, highlighted by DS internal deictics that refer to $\mathrm{L}_{1} \neq \mathrm{L}_{0}$ (L being the Locutor)]

Deictic Centre ${ }_{0}$ :Speaker $/ \mathrm{L}=\mathrm{L}_{0} ; \mathrm{T}=\mathrm{T}_{0}$.

Deictic Centre $1: \mathrm{L}=\mathrm{L}_{1} ; \mathrm{T}=\mathrm{T}_{1}$ (before $\mathrm{T}_{0}$ ).

$\mathrm{L}_{0}$ to $\mathrm{T}_{0}\{$ Marianna told me:

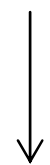

DS

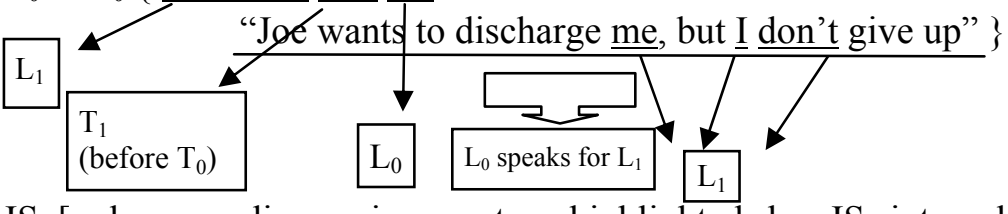

IS [only one discoursive centre, highlighted by IS internal deictics that refer to $\mathrm{L}_{0}$.]

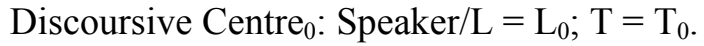

$\mathrm{L}_{0}$ to $\mathrm{T}_{0}$ \{ Marianna told me that Joe wants to discharge $\underline{\text { me, but } \mathrm{I} \text { don't }}$
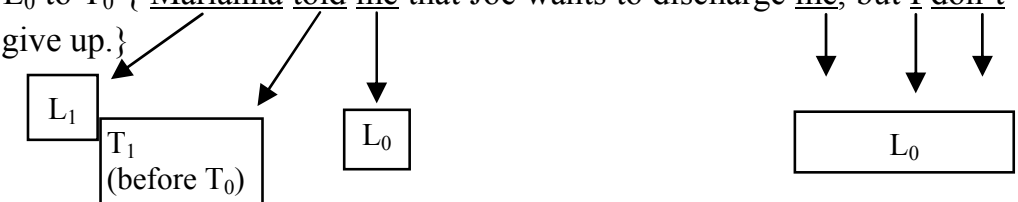

The deictic account of DS and IS clearly shows that reporting phenomena strongly implicate cognitive processes strictly related to what is called perspective taking, i.e., the capacity to assume different points of view of what's happening/happened/will happen. The way a speaker reports other people's words can in fact tell us much about how he has lived that event, shows us quite clearly what he understood of what has been told him and how. It is not an easy task: children take years to achieve a complete capacity of perspective taking (that is strictly related with the full development of the theory of mind) and it is not absolutely sure that all will reach 
18 Reported Speech: Towards a Definition as a Communicative and

the same level of it. ${ }^{10}$

As underlined earlier, this phenomenon involves very closely the problem of assuming responsibility about what is reported. Here the difference between DS and IS can result very deep.

In reporting in the direct form, the speaker has "simply" to cut his speech, making (or even without making it, as it is not necessary) an introduction containing a verb of saying, and to utter the words he attributes to another enunciative plan. This kind of embedding is simpler because it is iconic and ostensive: all the speaker has to do is to mark in some way (with prosody, mimic, gesture etc.) that the main utterance is going to be interrupted to let another one begin.

That is the reason why, as speech reporting can be considered universal, the direct form seems to be universal as well.

Scholars on the other hand do not agree about the universal status of other forms of RS, and, first of all, of IS. Cultural factors can deeply influence the RS pragmatics, making it different from one language to another, and excluding or modifying, one or more forms and their uses.

The following is what Li concludes about his analysis of RS in Paez, Navajo and Amjaric language and culture:

10 Theory of mind is the ability to interpret behaviour in terms of underlying mental states, such as intentions, beliefs, and desires (Cohen 1995, Wellman \& Lagattuta 2000). For example, most normally developing adults understand that other people have different beliefs and desires from their own and that a person's actions are based on his or her own beliefs and desires. The term 'theory of mind' was coined by Premack \& Woodruff (1978) and is often used to refer to the ability to attribute mental states and to use these invisible postulates to explain behaviour in everyday life. Premack \& Woodruff defined theory of mind as the ability to ascribe mental states to oneself and to others. The ability to ascribe these mental states was called a 'theory' because mental states are not observable. Premack \& Woodruff also used the term 'theory' as mental constructs of states of mind are used to predict behaviour. 
Direct speech is universal; indirect speech is not. Paez, for example, is a language without indirect speech. [...] Other known examples of languages without indirect speech are Navajo and Amharic (Li 1986: 39).

Anyway, other researchers anyway tend to attribute to IS the same universal feature of DS. Massamba (1986: 118), for example, comparing English and Swahili, claims that even «the notion on indirect speech has indications of being a universal phenomenon».

Some other scholars, as Ebert, who investigated the use of RS in some languages of Nepal, put the question in another terms. According to Ebert, in fact, the difference between DS and IS is not as clear-cut as it may seem, and data from conversation analysis show that ambiguous cases are much more common than non ambiguous ones:

The idea that languages make a clear distinction between direct and indirect speech is for most part a grammatical fiction. In normal conversation, direct speech may fade into indirect and vice versa. [...] The distinction between direct and indirect speech is probably not a universal phenomenon (Ebert 1986: 156).

In the conclusion of his study of RS in Danish, Haberland seems to provide the best solution about this problem. No doubt that RS is an universal, but, when we observe the forms in which it is realized, searching which of them can be considered universal and which is not, we cannot forget the cultural, literary and normative grammatical roots of the main definitions. So, it is better to intend the two main forms of RS as two tendencies, as two different ways to orientate the reported speech with respect to the matrix-speech. In this sense, maybe it is more probable that a certain kind of opposition, between a pluri-oriented speech - that more or less can correspond to DS- 
20 Reported Speech: Towards a Definition as a Communicative and

and a mono-oriented speech - that more or less can correspond to IS-is universal.

We started off by asking whether reported speech was a universal of linguistic action. We still hardly have the right to doubt this. We also asked whether the direct/indirect report distinction has any claim to be a universal as well. Our material from spoken Danish suggest that there is a clear basis for assuming that there are two basic ways of orientation in reporting speech which could be called direct and indirect speech. It is doubtful whether they make it possible to classify reports into two mutually exclusive and clearly distinguishable sets. To be more precise, they can be interpreted as two tendencies. This makes us ask if the clear-cut division between direct and indirect speech, mainly developed on the model of Latin and Classical Greek, and in different ways applied to a handful (but not even all) of European literary languages (of which Danish is one), ever really was as clear as it appeared from the point of view of the study of the literature of those languages in certain historical periods (Haberland 1986: 258).

\section{The Acquisition of RS in L1 and L2}

Evidences coming from the few researches about RS in L1 acquisition show that the direct form of RS is the first to be learnt by children.

Studying the whole process of acquisition of Swedish, Nordquist (2001), for example, has found that:

1. Children start using RS about 26 months in the direct form, while the indirect form starts to appear later, about 35 months;

2. The development of RS is strictly linked to the development of the cognitive decentralization capacity, that is the 
formation and the development of the theory of mind;

3. The ways children of about 3 years (i.e., 36 months, so able to use both the main RS forms) use RS show a clear pragmatic awareness, since different RS forms are used in different types of communicative activities.

RS, according to some authors as Wolf \& Hicks (1989) and Blum-Kulka (2004), represents a huge and important part of the capacity for intertextuality, i.e., the awareness that the daily conversational spoken language is a very rich mix of voices. Children learn very early to distinguish the different voices: the longitudinal study of the ways in which children between 2 and 7 years play games show that «the understanding of text as multivoiced emerges early enough to be considered a fundamental aspect of what young speakers learn about discourse» (Wolf-Hicks 1989: 333). Furthermore, already when they are 3 children are actually able to mark (through prosody, deictics and the sentence type) the distinction between the narrative co-text and characters' dialogue.

It is strictly linked to intertextuality also the transformational process that, as the capacity of speech representation grows up, children, according to Hickmann (1993), operate on dialogues making them become complete narrative texts. The results of her sperimentation - in which adults and children from 4 to 10 years report dialogues taken from stories provided for this purpose- have shown a clear preference by younger children for reporting ways that do not require explicit linking between the narrative co-text and RS (as re-enacting or voicing, i.e., DS without any introduction). Older children, instead, «framed speech events systematically with direct reports and the adults did so as often with direct and indirect reports» (Hickmann 1993: 83).

If researches about the acquisition of RS in L1 are few, researches in L2 are even fewer, and generally deal only with the 
22 Reported Speech: Towards a Definition as a Communicative and

syntactical features of the problem. ${ }^{11}$

A very recent study just about the acquisition of RS in Italian, made by who writes, confirms once again the priority, both in logic and chronologically sense, of direct form, even it would be more correct saying direct forms, since there is a clear acquisitional progression toward the complete mastery of DS. The main findings of the study reveal in fact that RS is a high level structure, in the sense that it needs a set of other linguistic features to be just learnt and to develop itself. Before having a basic vocabulary and a minimum degree of morphological development it is not possible to have the ability of making any reporting action. ${ }^{12}$ As a result, while for L1 RS acquisition the prerequisites correspond to the development of a basic theory of mind, for L2 acquisition they are just of a linguistic nature (lexical, morphological and syntactical) since learners of a L2 are supposed to have already completely developed their theory of mind in their L1.

The main results of the sperimentational research, the first carried out in particular about RS in L2 acquisition, consist in the drafting of a complete acquisitional sequence of RS, articulated in four main stages:

1. the first is characterized by the absence of RS (while the informant is learning other linguistic structures that will be used after for RS) ${ }^{13}$;

${ }^{11}$ For Italian language, for example, there are only some data about the acquisition of the different types of subordinate sentences. From this data one can select the findings about completive sentences corresponding to IS (Calleri et al. 2003).

12 The study has been based on the analysis of four focus groups made with young students of Italian as L2 participating to the Erasmus programme in Italy. The four focus group conversations have been videotaped and afterwards analyzed by means of CHILDES project (MacWhinney 1995).

13 This phase is not documented within the research since the participants, in order to be able to bear a focus group session, had not to be still in the very early stage of acquisition. 
2. in the second there is the emergence of the first form of RS, i.e., DS without any introduction, fulfilling only basic narrative functions;

(12) *MOD: al ritorno dalla discoteca conoscete qualcuno in discoteca che vi accompagna. ${ }^{14}$

[*MOD: going back from the disco you know someone in the disco who accompanies you]

*MAR: sì anche $+" \%$.

[MAR: yes also +"/. ]

+ " eh -' passaggio passaggio $\mathrm{xx!}$

[+" eh-' ride ride $\mathrm{xx}$ !]

\%act: fa il gesto come per fermare una macchina

[\%act: gestures as to stop a car]

*MOD: poi di solito siccome siete spagnole penso che $+/$.

[*MOD: then usually as you are Spanish I think that $+/$.]

*DIA: +" ah siete Erasmus -'< <a bene $>$ [?] uff!

[*DIA: +" ah you are Erasmus-' $<$ well $>$ [?] uff!]

3. in the third phase, next to more complex forms of DS there are the first forms of IS, and the range of RS functions becomes more and more wider;

14 All the examples are written in CHAT format: each line codes only one utterance; each line begins with an asterisk; after the asterisk comes a threeletter code in upper case letters for the participant who was the speaker of the utterance being coded $(\mathrm{MOD}=$ moderator [L1 Italian], MAR=Maria [L1 Spanish], DIA=Diana $\quad[\mathrm{L} 1=$ Spanish $], \quad \mathrm{XAN}=\mathrm{Xana} \quad[\mathrm{L} 1=$ Portuguese $], \quad \mathrm{STE}=$ Stephanie $[\mathrm{L} 1=$ Neerladese $], \mathrm{KAT}=$ Katherine $[\mathrm{L} 1=\mathrm{German}], \mathrm{LOR}=$ Lorena $[\mathrm{L} 1=\mathrm{Spanish}]$ ); special utterance terminators: $+/=$ =interruption, $+\%$.=quotation follows on next line, +"=quoted utterance follows, ["]=quotation mark, [?]=best guess; $\mathrm{xx}=$ unintelligible speech, :=lengthened syllable, $\left[{ }^{*}\right]=$ error marking, \#=pause, text(text) $=$ noncompletion of a word, \%act $=$ specifies actions made by the speaker. 
24 Reported Speech: Towards a Definition as a Communicative and

(13) *XAN: noi sempre chiediamo +"/.

[*XAN: we always ask $+/ "$.

+" che vuol dire sparire ["]?

DS with a complete introduction

[+" what does it mean to disappear ["]?]

(14) *KAT: e: la donna allo sportello ha detto che:

[*KAT: and the woman at the front desk said that]

questa volta non è un treno ma un sostituto(re) un pullman.

IS with non correct tense

[this time it is not a train but a substitute a bus.]

(15) *STE: 1' ho fatto una volta per: Sara e Ester e Diana e Ana [*STE: I did it once for Sara and Ester and Diana and Ana] e loro hanno detto [and they said that] che era molto bene [*]. IS [it was very well [*]]

4. in the fourth and last phase the informant is able to use all the RS forms for the fulfilment of all functions and sub-functions.

(16) *LOR: a me una volta mi hanno [*] arrivato a dire [*LOR: to me once they were [*] went so far as to say] le mongoloidi che abitano con me [the mongoloids who lived with me] che si $\left.{ }^{*}\right]$ io dicevo male al calcio insultavo la mamma [that ef [*] I said bad to football I insulted the mom]

che la mamma $<$ di loro $[*]>$ era puttana

[that the mom $<$ of them [*]> was a bitch]

IS2

che dovevo stare zitta.

[that I had to be silent] 
$[\ldots]$

+" ma tu devi stare zitta!

[+" but you must be silent!]

DS1

così

[this way]

e come e [*] questo è un esempio +"/.

[and like and [*] this is an example]

$+"$ devi stare zitta!

[+" you must be silent!]

DS2

+" perché se tu dici male a la [*] Juve-, .

[+" because if you say bad to Juve-,]

DS3

+ " dici che mia mamma è una puttana

[+" you say that my mom is a bitch]

DS4

$+"$ e io m'incazzo! \#

[+" and I get angry!\#]

DS5

\section{Conclusions: What is Universal in RS}

Coming to the end of this excursus, we have gathered some more evidences in order to define RS as a universal phenomenon.

Since giving voice to other people's words and thoughtsessentially to narrate past events, imagine future ones or meditate about situations - is one of the basic communicative activities of humans, it is not possible that a language without any means to report speech does actually exist. So, there is no doubt that RS, as a basic communicative function essentially linked to narrative needs, is universal, and must be fulfilled linguistically in some way.

But several doubts still remain about which are the universal formal sides of RS, i.e., which forms, corresponding to RS, are universal, and why.

Some authors affirm that even the classical opposition between direct and indirect speech is universal, some others mitigate this 
26 Reported Speech: Towards a Definition as a Communicative and

claim observing that this opposition has not to be meant in the grammatical way, that is in absolute terms. According to the latter perspective, since daily spontaneous conversations show many cases of fading of one form to another, there is not a clear-cut limit between the two forms, and they have to be red in terms of two tendencies, two different pragmatic ways of embedding speeches into speech.

For some others, as Li, only direct speech is universal, while other forms are not: in any case, it seems that all the studies lead to the conclusion that there is a basic form of RS fulfilment, corresponding to the direct speech, which is universal as well.

The basic nature of DS seems to be confirmed by the results coming from researches about RS place in L1 and L2 acquisition. The stage, the way in which RS is learnt and it develops confirms in fact its prototypicity, perhaps related to its iconic structure, even if we still need more evidences from more investigations dealing with not only occidental languages, but from languages of all over the world.

\section{References}

Baynham, M. 1996. Direct Speech: What's it Doing in Non-narrative Discourse? Journal of Pragmatics 25, 61-81.

Blum-Kulka, S. 2004. The Role of Peer Interaction in Later Pragmatic

Development: The Case of Speech Representation. In R. Berman (ed.),

Language Development across Childhood and Adolescence: Psycholinguistic and Crosslinguistic Perspectives. TILAR Series 191210. Amsterdam \& New York: John Benjamins.

Boogaart, R. 1996. Tense and Temporal Ordering in English and Dutch Indirect Speech. In T. Janssen \& W. Wurff (eds.), Reported Speech: Forms and Functions of the Verb 21-236. Amsterdam: John Benjamins. Bruner, J. 1986. Actual Minds, Possible Worlds. Cambridge, MA: Harvard 
University Press.

Calaresu, M. 2000. Il discorso riportato. Una prospettiva testuale. Modena: Il Fiorino. . 2004. Testuali parole. La dimensione pragmatica e testuale del discorso riportato. Milano: Franco Angeli.

Calleri, D., M. Chini, P. Cordin, \& S. Ferraris. 2003. Confronti tra l'acquisizione di Italiano L1 e l'acquisizione di Italiano L2. In A. Ramat (ed.), Verso llitaliano. Percorsi e strategie di acquisizione 220-253. Roma: Carocci.

Castellano, C., R. Bahr, \& E. Silliman. 2003. Oral-written Contrasts of Quoted Dialogue Frames in Older Children. Paper Presented at the Annual Convention of the American Speech-Language-Hearing Association, Chicago, Illinois, November 15, 2003.

Clark, H. \& R. Gerrig. 1990. Quotations as Demonstrations. Language 66. 4, 764-805.

Ebert, K. 1986. Reported Speech in Some Languages of Nepal. In F. Coulmas (ed.), Direct and Indirect Speech 145-160. Amsterdam: Mouton de Gruyter.

Gonzàlez, M. 2004. Pragmatic Markers in Oral Narrative. The Case of English and Catalan. Amsterdam-Philadelphia: John Benjamins.

Haberland, H. 1986. Reported Speech in Danish. In F. Coulmas (ed.), Direct and Indirect Speech 219-254. Amsterdam: Mouton de Gruyter.

Haverkate, H. 1996. Modal Patterns of Direct and Indirect Discourse in Peninsular Spanish: An Analysis within the Framework of Speech Act Typology. In T. Janssen \& W. Wurff (eds.), Reported Speech: Forms and Functions of the Verb 97-120. Amsterdam: John Benjamins.

Hickmann, M. 1993. The Boundaries of Reported Speech in Narrative Discourse: Some Developmental Aspects in Reflexive Language. In J. Lucy (ed.), Reflexive Language 63-88. Cambridge: Cambridge University Press.

Hockett, C. 1966. The Problem of Universals in Language. In J. Greenberg (ed.), Universals of Languages 1-29. Cambridge: Cambridge University Press. 
28 Reported Speech: Towards a Definition as a Communicative and

1968. The State of the Art. L'Aja: Mouton de Gruyter.

Labov, W. 1972. Language in the Inner City. Philadelphia, PA: University of Pennsylvania Press.

Labov, W. \& J. Waletsky. 1967. Speech Actions and Reactions in Personal Narrative. In D. Tannen (ed.), Analyzing Discourse: Text and Talk 219247. Washington D.C.: Georgetown University Press.

Li, Ch. 1986. Direct and Indirect Speech: A Functional Study. In F. Coulmas (ed.), Direct and Indirect Speech 29-46. Amsterdam: Mouton de Gruyter.

Massamba, D. 1986. Reported Speech in Swahili. In F. Coulmas (ed.), Direct and Indirect Speech 99-120. Amsterdam: Mouton de Gruyter.

Maynard, S. 1986. The Particle -o and Content-oriented Indirect Speech in Japanese Written Discourse. In F. Coulmas (ed.), Direct and Indirect Speech 179-200. Amsterdam: Mouton de Gruyter.

Nordqvist, Å. 2001. The Use of Direct and Indirect Speech by $11 / 2$ - to $4-$ year-olds. Psychology of Language and Communication 5.1, 21-45.

Simone, R. 1990. Fondamenti di linguistica. Bari: Laterza.

Tannen, D. 1988. Hearing Voices in Conversation, Fiction, and Mixed Genres. In D. Tannen (ed.), Linguistics in Context: Connecting Observation and Understanding 89-113. Norwood, NJ: Ablex. . 1989. Talking Voices. Repetition, Dialogue, and Imagery in Conversational Discourse. Cambridge: Cambridge University Press.

Vincent, D. \& L. Perrin. 1999. On the Narrative vs. Non-narrative Functions of Reported Speech: A Socio-pragmatic Study. Journal of Sociolinguistics 3.3, 291-313.

Wolf, D. \& D. Hicks. 1989. The Voices within Narratives: The Development of Intertextuality in Young Children's Stories. Discourses and Processes 12, 329-351.

Wurff, W. 1996. Sequence of Tenses in English and Bengali. In T. Janssen $\&$ W. Wurff (eds.), Reported Speech: Forms and Functions of the Verb 261-288. Amsterdam: John Benjamins. 